\title{
Recombinant Lactobacillus plantarum expressing and secreting heterologous oxalate decarboxylase prevents renal calcium oxalate stone deposition in experimental rats
}

Ponnusamy Sasikumar ${ }^{1}$, Sivasamy Gomathi ${ }^{1}$, Kolandaswamy Anbazhagan², Albert Abhishek', Eldho Paul ${ }^{1}$, Varadaraj Vasudevan ${ }^{1}$, Sundaresan Sasikumar ${ }^{1}$ and Govindan Sadasivam Selvam ${ }^{*}$

\begin{abstract}
Background: Calcium oxalate $(\mathrm{CaOx})$ is the major constituent of about $75 \%$ of all urinary stone and the secondary hyperoxaluria is a primary risk factor. Current treatment options for the patients with hyperoxaluria and $\mathrm{CaOx}$ stone diseases are limited. Oxalate degrading bacteria might have beneficial effects on urinary oxalate excretion resulting from decreased intestinal oxalate concentration and absorption. Thus, the aim of the present study is to examine the in vivo oxalate degrading ability of genetically engineered Lactobacillus plantarum (L. plantarum) that constitutively expressing and secreting heterologous oxalate decarboxylase (OxdC) for prevention of $\mathrm{CaOx}$ stone formation in rats. The recombinants strain of L. plantarum that constitutively secreting (WCFS1OxdC) and non-secreting ( $\mathrm{NC8OxdC)} \mathrm{OxdC} \mathrm{has} \mathrm{been} \mathrm{developed} \mathrm{by} \mathrm{using} \mathrm{expression} \mathrm{vector} \mathrm{pSIP401.} \mathrm{The} \mathrm{in} \mathrm{vivo} \mathrm{oxalate}$ degradation ability for this recombinants strain was carried out in a male wistar albino rats. The group I control; groups II, III, IV and V rats were fed with $5 \%$ potassium oxalate diet and $14^{\text {th }}$ day onwards group II, III, IV and V were received esophageal gavage of L. plantarum WCFS1, WCFS1OxdC and NC8OxdC respectively for 2-week period. The urinary and serum biochemistry and histopathology of the kidney were carried out. The experimental data were analyzed using one-way ANOVA followed by Duncan's multiple-range test.
\end{abstract}

Results: Recombinants L. plantarum constitutively express and secretes the functional OxdC and could degrade the oxalate up to $70-77 \%$ under in vitro. The recombinant bacterial treated rats in groups IV and $V$ showed significant reduction of urinary oxalate, calcium, uric acid, creatinine and serum uric acid, BUN/creatinine ratio compared to group II and III rats $(P<0.05)$. Oxalate levels in kidney homogenate of groups IV and V were showed significant reduction than group II and III rats $(P<0.05)$. Microscopic observations revealed a high score (4+) of CaOx crystal in kidneys of groups II and III, whereas no crystal in group IV and a lower score (1+) in group V.

Conclusion: The present results indicate that artificial colonization of recombinant strain, WCFS1 OxdC and NC8OxdC, capable of reduce urinary oxalate excretion and $\mathrm{CaOx}$ crystal deposition by increased intestinal oxalate degradation.

Keywords: Calcium oxalate stone formation, Hyperoxaluria, Lactobacillus plantarum, Oxalate-degrading bacteria, Oxalate Decarboxylase, Urolithiasis

\footnotetext{
* Correspondence: drselvamgsbiochem@rediffmail.com

'Department of Biochemistry, Centre for Advanced Studies in Organismal and Functional Genomics, School of Biological Sciences, Madurai Kamaraj University, Madurai 625 021, India

Full list of author information is available at the end of the article
} 


\section{Background}

The lifetime risk for kidney stone disease currently exceeds $6-12 \%$ in the general population, and its prevalence appears to increase steadily in both sexes [1]. Calcium oxalate $(\mathrm{CaOx})$ is the major constituent of about $75 \%$ of all urinary stones population [2]. Secondary hyperoxaluria either based on intestinal hyperabsorption of oxalate or high intake of oxalate is considered a crucial risk factor in the pathogenesis of $\mathrm{CaOx}$ stone formation [3]. Urinary oxalate (UOx) is predominantly derived from endogenous production of oxalate from ingested or metabolically generated precursors and from the diet. It has been suggested that dietary contribution to UOx excretion is up to $50 \%$ [4]. Some foods, particularly vegetables such as spinach, wheat bran, and cereals contain high amounts of oxalic acid [5]. An increased absorption of oxalate has been demonstrated in $46 \%$ of patients with $\mathrm{CaOx}$ kidney stone [6]. Existing treatments for patients with $\mathrm{CaOx}$ urolithiasis are limited and do not always lead to sufficient reduction in UOx excretion. Even though, the invasive technologies (shockwave lithotripsy, ureteroscopy, percutaneous stone extractions) exist, these techniques have its own disadvantages like renal injury, recurrent stone formation with a prevalence of $50 \%$ over 10 years.

Another possible approach to prevent renal stone recurrence is to reduce the consumption of oxalate rich foods. Although, such dietary restriction is commonly advised to reduce stone recurrence, its long-term effectiveness is uncertain and would probably lead to deficiency in essential nutrients [7]. Thus, other methods meant to reduce intestinal oxalate absorption are required. Among them, the microbiological approach has received increasing attention in recent years. Oxalate degrading bacteria is being considered for degrading intestinal oxalate to prevent $\mathrm{CaOx}$ stone formation. Starting in 1980 with the discovery of an oxalotropic gut-resident bacterium Oxalobacter formigenes (O. formigenes) leading to a new research direction for the management of $\mathrm{CaOx}$ urolithiasis. O. formigenes is an anaerobic bacterium that naturally colonizes the colon of vertebrates, including humans, and utilizes oxalic acid as its sole source of energy [8]. The use of O. formigenes in reduction of oxalate excretion in urine and prevention of renal stone recurrence was elaborately studied $[9,10]$. However, endogenously derived oxalate supplement was needed to colonize the bacterium in the gut. Hence, usage of this bacterium raises some concern and the other side Oxalobacter strains are not considered mainstream therapy primarily due to lack of sufficient clinical data supporting their use. Earlier, reports have shown that lactic acid bacteria (LAB) have no influence on reduction of hyperoxaluria [11]. The discovery of oxalate decarboxylase (oxdC) gene in Bacillus subtilis (B. subtilis), which breaks down the oxalate in to formate and $\mathrm{CO}_{2}$ raise a new hope to mitigate hyperoxaluria [12]. In subsequent years various research groups have demonstrated the use of oxalate decarboxylase $(\mathrm{OxdC})$ protein in degradation of oxalate by in vitro and in vivo experiment for the treatment of hyperoxaluria [13-15].

Hence, we designed a strategy to engineer LAB component of intestinal microflora by heterologous expression of oxdC gene from B. subtilis origin. Artificial colonization with this recombinant strain may decrease the intestinal oxalate absorption and renal excretion by degrading dietary oxalate. In the present work, in vivo oxalate degrading potency of two recombinants Lactobacillus plantarum (L. plantarum) strains such as OxdC-secretory WCFS1OxdC [16] and non-secretory NC8OxdC [17] was investigated in rats fed with oxalate-rich diet.

\section{Methods}

\section{Chemicals and reagents}

Primers used were synthesized and procured from Sigma Aldrich (USA) [Additional file 1]. The experimental diet containing $5 \%$ potassium oxalate was procured from National Institute of Nutrition (NIN, Hyderabad, India). Hyperoxaluria and calcium oxalate crystal were induced in a rat model as described elsewhere [18]. Urinary and serum biochemical parameters were measured in semi automated photometer 5010 V5 + (Robert Riele GmbH, Germany) using commercially available kits [Additional file 2].

\section{Bacterial strains, media and growth conditions}

The bacterial strains and plasmids used in this study are listed in table 1. L. plantarum was grown in deManRogosa-Sharpe (MRS) media at $30^{\circ} \mathrm{C}$ without shaking.

\section{Table 1 Bacterial strains and plasmids used in this work}

\begin{tabular}{|c|c|c|}
\hline $\begin{array}{l}\text { Strains \& } \\
\text { plasmids }\end{array}$ & Characteristics $^{\alpha}$ & Source/references \\
\hline \multicolumn{3}{|l|}{ Strains } \\
\hline \multicolumn{3}{|l|}{ L. plantarum } \\
\hline WCFS1* & $\begin{array}{l}\text { Host strain, Plasmid-free, } \\
\text { silage isolate }\end{array}$ & Kleerebezem et al., [19] \\
\hline NC8OxdC & $\begin{array}{l}\text { p256/pUC(pGEM)ori; } \\
\text { PldhlioxdC;Erm }{ }^{r}\end{array}$ & Kolandasamy et al., [17] \\
\hline WCFS1OxdC & $\begin{array}{l}\text { p256/pUC(pGEM)ori; } P_{\text {IdhL; }} \\
\text { sp } \text { Lp_O373 fused to the }_{\text {oxdC; Erm }}\end{array}$ & Sasikumar et al., [16] \\
\hline
\end{tabular}

Plasmid

$\begin{array}{lll}\text { pLdhlOxdC } & \text { p256/pUC(pGEM)ori; } & \text { Kolandasamy et al., [17] } \\ & \text { PldhLiOxdC;Erm }{ }^{r} & \\ \text { pLdhl03730xdC } & \begin{array}{l}\text { p256/pUC(pGEM)ori;PIahL; } \\ \text { splp_0373 fused to the } \\ \text { oxdC; Erm }\end{array} & \text { Sasikumar et al., [16] } \\ & & \end{array}$

${ }^{\alpha}$ For strains, genotypic and phenotypic characteristics are given; for plasmid, plasmid and cloned-cassette characteristics are given; Erm ${ }^{r}$, : resistance to erythromycin. *L. plantarum WCFS1 is a single colony isolate of strain NCIM8826 (Kleerebezem et al., 2003) [19]. 
Erythromycin was added to the MRS at a final concentration of $5 \mu \mathrm{g} / \mathrm{mL}$ for the growth of recombinant L. plantarum.

\section{Manipulation of recombinant Lactobacillus plantarum}

The genetically engineered OxdC-secreting L. plantarum WCFS1OxdC was developed [16] and the construction of non-secreting $L$. plantarum NC8OxdC was described [17] and both the recombinants and non-recombinant L. plantarum WCFS1 strain was used to evaluate in vivo oxalate degradation in rat model.

\section{Preparation of live bacterial inocula}

The recombinant WCFS1OxdC, NC8OxdC and the non-recombinant strain of $L$. plantarum WCFS1 was grown in MRS medium. The bacterial number per milliliter of cultures was estimated using spectrophotometric measurements $\left(\mathrm{OD}_{600}\right)$ and cellular pellets were harvested by centrifugation at $5000 \mathrm{rpm}$. The pellet was washed and resuspended in sterile phosphate buffered saline (PBS) at $\left(5 \times 10^{10} \mathrm{CFU} \mathrm{mL}{ }^{-1}\right)[10]$.

\section{Animals and study design}

Male wistar albino rats (130-140 g) were used in this study and the experimental procedure was approved by the Internal Research and Review Board, Ethical Clearance, Biosafety and Animal Welfare Committee of Madurai Kamaraj University. The rats were divided into five groups ( $n=6$ /group) and were kept at $27 \pm 2^{\circ} \mathrm{C}$ with a $12 \mathrm{~h}$ light and dark cycle. Group I control rats received standard rat chow and the experimental group rats (II, III, IV and V) received chow mixed with $5 \%$ potassium oxalate (weight/weight oxalate/chow) to induce hyperoxaluria [18]. The rats in group III, IV and V were orally administered with non-recombinant and recombinants $L$. plantarum respectively by esophageal gavage of $\left(5 \times 10^{10} \mathrm{CFU} \mathrm{mL}{ }^{-1}\right.$ day $^{-1}$ ) bacterium [10]. Day 14 onwards the group II rats were administrated by esophageal gavage with $1 \mathrm{~mL} \mathrm{PBS} \mathrm{day}{ }^{-1}$; while group III were administrated with non-recombinant $L$. plantarum; group IV and V rats were administrated with recombinant $L$. plantarum harboring plasmid pLdhl0373OxdC and pLdhlOxdC respectively. At the end of the fourth week, the animals were sacrificed and serum samples was separated. Kidney tissues were processed for localization of crystals, biochemical and various other morphological analyses.

\section{Urine collection and analysis}

On the day $0,7,14,21$ and 28 the rats were placed in metabolic cages and $24 \mathrm{~h}$ urine was collected in presence of $0.02 \%$ sodium azide to prevent bacterial growth. After determining urinary volume and $\mathrm{pH}$, urine was aliquot for various assays. Urinary oxalate, calcium, uric acid, creatinine and urea were also determined using commercial kit in semiautomatic photometer according to manufacturer's protocol. Each week one-hour urine samples were collected and examined by polarized light microscopy to analyze the presence of $\mathrm{CaOx}$ crystalluria and scored on a basis of $0-3+[20]$.

\section{Determination of recombinant $L$. plantarum in feces}

Determination of recombinant $L$. plantarum in feces was carried out by culture methods as well as by PCR as described elsewhere [10].

\section{Serum parameters analysis}

Serum parameters such as creatinine, calcium, urea, uric acid, protein and $\mathrm{C}$-reactive protein $(\mathrm{CRP})$ were measured

L. plantarum WCFS1OxdC : Expression cassette of plasmid pLdh10373sOxdC

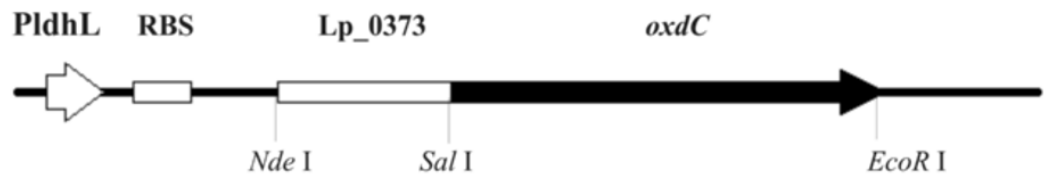

L. plantarum NC8OxdC: Expression cassette of plasmid pLdhlOxdC

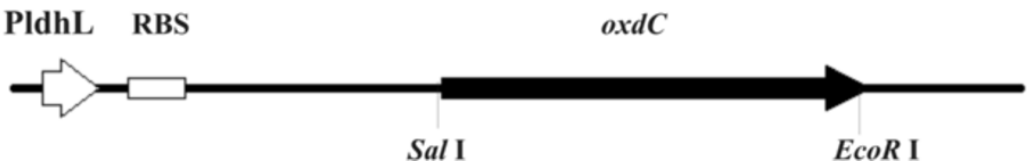

Figure 1 Schematic representation of expression cassettes of recombinant plasmids. L. plantarum WCFS1OxdC represents the recombinant strain harboring the plasmid pLdhl03730xdC for extracellular expression of OxdC; L. plantarum NC8OxdC indicates the recombinant strain harboring the plasmid pLdhlOxdC for intracellular expression of OxdC; PldhL: promoter, RBS: ribosomal binding site; Lp_0373: signal peptides; oxdC: oxalate decarboxylase; restriction sites also indicated. 


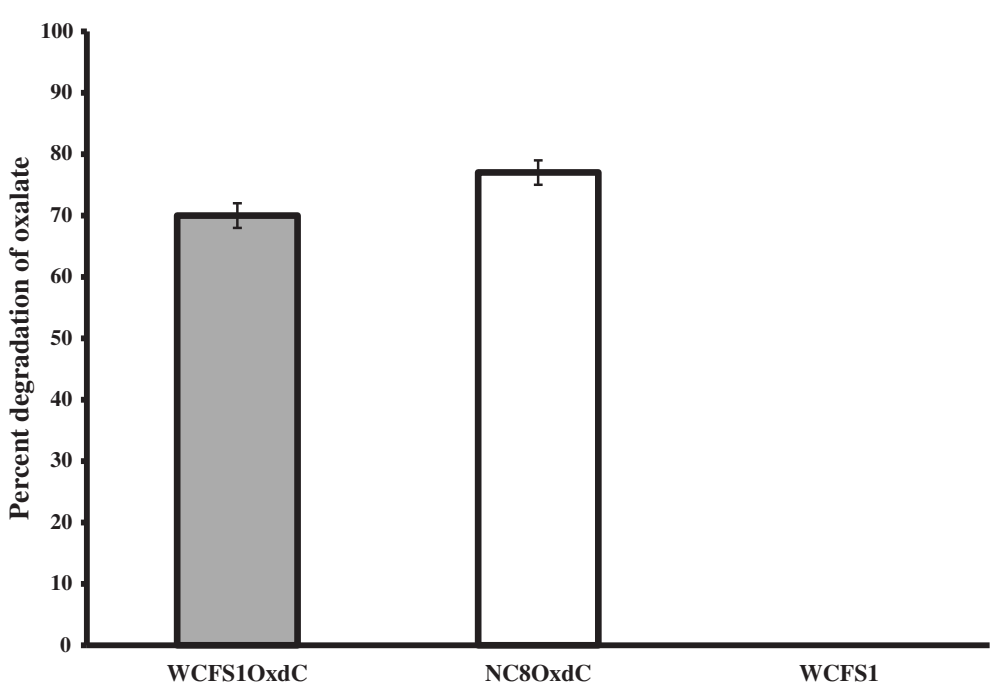

Figure 2 Percentage of in vitro oxalate degradation by recombinant and wild type L. plantarum. WCFS1OxdC: L. plantarum harboring the recombinant plasmid pLdhl03730xdC; NC8OxdC: L. plantarum harboring recombinant plasmid pLdhlOxdC; WCFS1: wild type L. plantarum. The error bar represents the standard deviation from three independent exprements.

Table 2 Urinary biochemistry profile

\begin{tabular}{|c|c|c|c|c|c|}
\hline Days $^{\alpha}$ & Group I $(n=6)$ & Group II & Group III & Group IV & Group V \\
\hline \multicolumn{6}{|c|}{ Bodyweight (g) } \\
\hline 0 & $140.40 \pm 1.24$ & $130.70 \pm 3.18$ & $131.01 \pm 3.42$ & $133.57 \pm 2.66$ & $133.38 \pm 2.27$ \\
\hline 7 & $173.49 \pm 2.34$ & $134.37 \pm 2.01^{\mathbf{a}^{*}}$ & $145.59 \pm 2.82^{\mathbf{a}^{*}}$ & $142.27 \pm 3.70^{\mathbf{a}^{*}}$ & $140.42 \pm 2.10^{\mathbf{a}^{*}}$ \\
\hline 14 & $218.31 \pm 3.32$ & $151.16 \pm 2.64$ & $160.88 \pm 2.69$ & $164.90 \pm 3.38$ & $150.82 \pm 3.01$ \\
\hline 21 & $240.39 \pm 2.75$ & $171.17 \pm 3.04$ & $180.17 \pm 3.25$ & $190.76 \pm 3.39$ & $171.42 \pm 3.35$ \\
\hline 28 & $261.11 \pm 2.87$ & $195.13 \pm 3.70^{\mathbf{a}^{*}}$ & $191.80 \pm 2.06^{\mathbf{a}^{*}}$ & $220.14 \pm 2.68^{\mathbf{a}^{*} \mathbf{b}^{*} \mathbf{c}^{*}}$ & $201.73 \pm 2.51^{\mathbf{a}^{*} \mathbf{b}^{*} \mathbf{c}^{*}}$ \\
\hline \multicolumn{6}{|c|}{ Urine $\mathrm{pH}$} \\
\hline 0 & $7.07 \pm 0.11$ & $6.83 \pm 0.26$ & $6.84 \pm 0.19$ & $6.74 \pm 0.25$ & $6.54 \pm 0.15$ \\
\hline 7 & $7.13 \pm 0.16$ & $7.08 \pm 0.18$ & $6.94 \pm 0.20$ & $7.11 \pm 0.18$ & $7.29 \pm 0.12$ \\
\hline 14 & $7.10 \pm 0.22$ & $6.94 \pm 0.30$ & $6.94 \pm 0.24$ & $6.97 \pm 0.20$ & $7.02 \pm 0.15$ \\
\hline 21 & $7.21 \pm 0.15$ & $6.44 \pm 0.19^{\mathbf{a}^{*}}$ & $6.55 \pm 0.12^{\mathbf{a}^{*}}$ & $6.86 \pm 0.21^{\mathbf{b}^{*} c^{*}}$ & $6.94 \pm 0.16$ \\
\hline 28 & $7.25 \pm 0.11$ & $6.09 \pm 0.07^{\mathbf{a}^{*}}$ & $6.16 \pm 0.08^{\mathbf{a}^{*}}$ & $6.90 \pm 0.17^{\mathbf{a}^{*} \mathbf{b}^{*} \mathbf{c}^{*}}$ & $6.79 \pm 0.13^{\mathbf{a}^{*} \mathbf{b}^{*} \mathbf{c}^{*}}$ \\
\hline \multicolumn{6}{|c|}{ Uric acid (mg/24 h) } \\
\hline 0 & $0.05 \pm 0.01$ & $0.09 \pm 0.01$ & $0.06 \pm 0.01$ & $0.05 \pm 0.01$ & $0.05 \pm 0.01$ \\
\hline 7 & $0.12 \pm 0.01$ & $0.14 \pm 0.01$ & $0.16 \pm 0.01$ & $0.07 \pm 0.01$ & $0.12 \pm 0.04$ \\
\hline 14 & $0.11 \pm 0.02$ & $0.18 \pm 0.01^{\mathbf{a}^{*}}$ & $0.19 \pm 0.01^{\mathbf{a}^{*}}$ & $0.09 \pm 0.01^{\mathbf{b}^{*} \mathbf{c}^{*}}$ & $0.14 \pm 0.01^{\mathbf{b}^{*} \mathbf{c}^{*}}$ \\
\hline 21 & $0.15 \pm 0.02$ & $0.21 \pm 0.02^{\mathbf{a}^{*}}$ & $0.25 \pm 0.03^{\mathbf{a}^{*}}$ & $0.11 \pm 0.03^{\mathbf{b}^{*} \mathbf{c}^{*}}$ & $0.15 \pm 0.01^{\mathbf{b}^{*} c^{*}}$ \\
\hline 28 & $0.17 \pm 0.02$ & $0.46 \pm 0.02^{a^{*}}$ & $0.39 \pm 0.03^{\mathrm{a}^{*}}$ & $0.12 \pm 0.01^{b^{*} c^{*}}$ & $0.18 \pm 0.02^{\mathbf{b}^{*} c^{*}}$ \\
\hline \multicolumn{6}{|c|}{ Creatinine $(\mathrm{mg} / 24 \mathrm{~h})$} \\
\hline 0 & $1.33 \pm 0.08$ & $1.39 \pm 0.18$ & $1.23 \pm 0.15$ & $1.11 \pm 0.11$ & $1.16 \pm 0.08$ \\
\hline 7 & $1.04 \pm 0.06$ & $1.50 \pm 0.16^{\mathrm{a}^{*}}$ & $1.69 \pm 0.26^{\mathbf{a}^{*}}$ & $1.41 \pm 0.11^{\mathbf{a}^{*}}$ & $1.73 \pm 0.10^{\mathbf{a}^{*}}$ \\
\hline 14 & $1.64 \pm 0.24$ & $1.73 \pm 0.13^{\mathbf{a}^{*}}$ & $2.82 \pm 0.29^{\mathbf{a}^{*}}$ & $1.61 \pm 0.18^{\mathrm{c}^{*}}$ & $1.95 \pm 0.18^{\mathrm{c}^{*}}$ \\
\hline 21 & $1.51 \pm 0.31$ & $2.71 \pm 0.19^{\mathbf{a}^{*}}$ & $3.19 \pm 0.22^{\mathbf{a}^{*}}$ & $2.07 \pm 0.09^{\mathbf{a}^{*} \mathbf{b}^{*} \mathbf{c}^{*}}$ & $2.30 \pm 0.16^{\mathbf{a}^{*} \mathbf{b}^{*} \mathrm{c}^{*}}$ \\
\hline 28 & $1.77 \pm 0.23$ & $3.69 \pm 0.30^{\mathbf{a}^{*}}$ & $3.52 \pm 0.19^{\mathbf{a}^{*}}$ & $2.52 \pm 0.14^{\mathbf{a}^{*} \mathbf{b}^{*} \mathbf{c}^{*}}$ & $3.07 \pm 0.61^{\mathbf{a}^{*} \mathbf{c}^{*}}$ \\
\hline
\end{tabular}

${ }^{a}$ Data are expressed as mean \pm SD. Comparisons are made against Group I (Control) ${ }^{a}$, Group II (lithiatic control) ${ }^{b}$ and Group III (Non-recombinant strain) . $^{c}$ $\mathrm{a}^{*} \mathrm{~b}^{*}$ and ${ }^{\mathrm{c}^{*}}$ indicates the mean value is significant at $\mathrm{p}<0.05$ against group I, II and III correspondingly. $\mathrm{n}=6$ rats each group. 

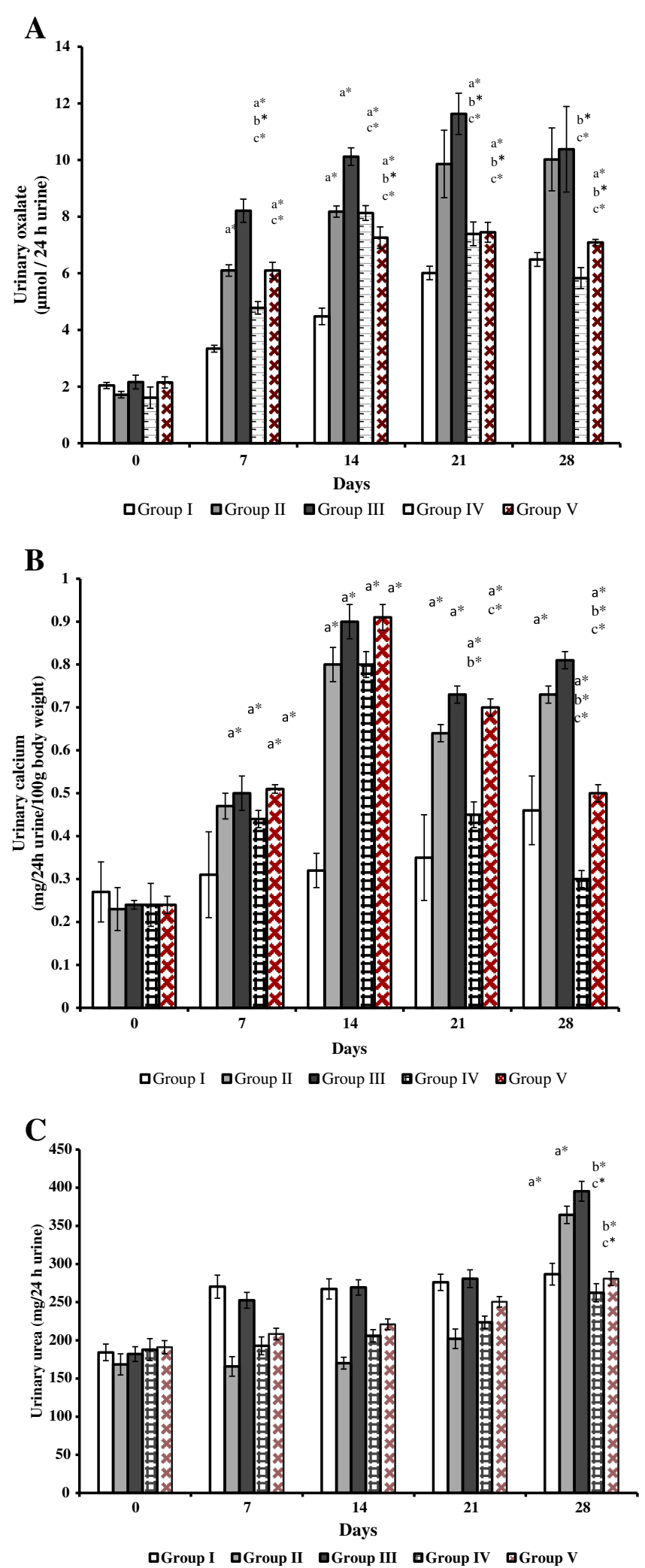

Figure 3 Urinary oxalate, calcium and urea excretions in control and experimental rats. (A) Urinary oxalate excretions in control and experimental rats (B) Urinary calcium excretions in control and experimental rats (C) Urinary urea concentrations in control and experimental rats. Comparisons are made against group I (Control) $)^{a}$, group II (lithiatic control) ${ }^{b}$ and group III (Non-recombinant strain). ${ }^{c}$ The mean value is significant at $p<0.05 . n=6$ rats each group. 
by using respective kits as suggested by manufacturer (Additional file 2).

\section{Analysis of oxalate and calcium in kidney homogenate}

A pair of kidney from each group rats was removed and a section of kidney was used for analysis of oxalate and calcium. Kidney tissue was rinsed with ice cold saline $(0.9 \% \mathrm{w} / \mathrm{v}$ sodium chloride) and repeatedly washed with $0.15 \mathrm{M} \mathrm{KCl}$, weighed, homogenized using $10 \% \mathrm{HCl}$ and was centrifuged at $2500 \mathrm{rpm}$ for $3 \mathrm{~min}$. The supernatant was used to determine oxalate and calcium. Oxalate concentration was determined manually by colorimetric method described elsewhere [21].

\section{RNA isolation and semi-quantitative RT-PCR}

The mRNA levels of glyceraldehyde-3 phosphate dehydrogenase (GAPDH), OPN, renin, and $A C E$ in the kidney were quantified by semi-quantitative reverse transcriptasepolymerase chain reaction (RT-PCR). [Additional file 3].

\section{Analysis of histopathology and $\mathrm{CaOx}$ crystal in kidney}

The kidney tissue from each group was fixed in 10\% neutral buffered formalin, trimmed, processed, and embedded in paraffin. Sections from each kidney were stained with hematoxylin and eosin and examined under light microscope for pathological analysis and polarized light microscope for visualizing $\mathrm{CaOx}$ crystal. The presence of $\mathrm{CaOx}$ crystal was scored on a basis of $0-5+[22] . \mathrm{CaOx}$ crystal present in each kidney tissue was examined by pizzolato staining methods [23]. Pathological analysis was examined with the help of qualified pathologist.

\section{Statistical analysis}

Data were expressed as mean $\pm \mathrm{SD}$. The statistical significance between subgroups was analyzed with one-way ANOVA followed by Duncan's multiple-range test using SPSS, software. Results were considered significant if the $P$ value $<0.05$.

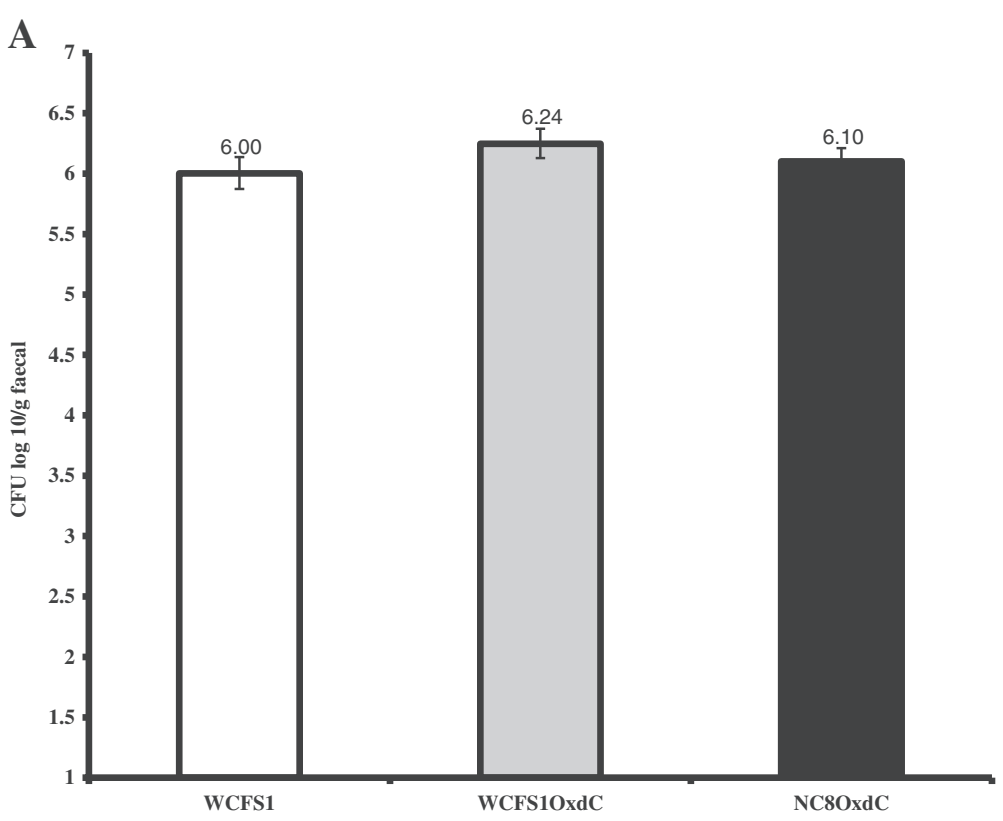

B

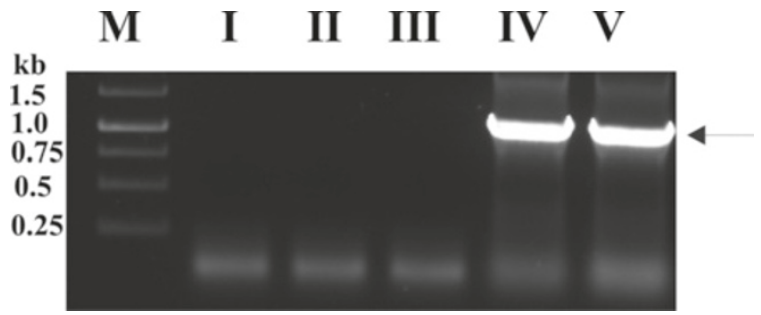

Figure 4 Colony forming units of wild type and recombinant L. plantarum in rat feces. (A) WCFS1 indicate wild type L. plantarum and WCFS1OxdC, NC8OxdC indicate recombinant L. plantarum harboring plasmid pLdhl03730xdC and pLdhlOxdC respectively. Results are expressed as mean of colony forming units (CFU) per gram of feces (B) Determination of recombinant L. plantarum in feces by PCR. I, II, III, IV and V indicate the respective group of rat, $\mathrm{M} ; 1 \mathrm{~kb}$ DNA Marker, Arrow indicate the PCR amplicon corresponding to $1.2 \mathrm{~kb}$ size of oxdC gene. 


\section{Results}

Engineered LAB efficiently degraded oxalate under in vitro The recombinant OxdC-secretory L. plantarum WCFS1OxdC harboring the recombinant vector pLdhl0373OxdC size of $4.7 \mathrm{~kb}$ and non-secretory L. plantarum NC8OxdC harboring the recombinant plasmid without signal peptide sequence $\mathrm{pLdhlOxdC}$ was used to analyze in vivo oxalate degradation in rat model. Schematic representation of expression cassette of recombinant plasmids used for secretion and expression of $\mathrm{OxdC}$ in the L. plantarum was shown in Figure 1. The OxdC-secreting WCFS1OxdC strain harboring plasmid (pLdhl0373OxdC) was consisting of constitutive promoter $\left(\mathrm{P}_{l d h L}\right)$ and signal peptide (Lp_0373) sequences, as a result the WCFS1OxdC strain secretes the functional $\mathrm{OxdC}$ at extracellular level and degrading $70 \%$ of extracellular oxalate (Figure 2). The specific activity of recombinant OxdC purified from recombinant strain of WCFS1OxdC was found to be $19.1 \mathrm{U} / \mathrm{mg}$ and secretion efficiency of the strain WCFS1OxdC shows that $25 \%$ of the OxdC produced was secreted into the medium. The OxdC non-secreting NC8OxdC strain which harboring recombinant plasmid (pLdhlOxdC), consisting of constitutive promoter $\left(\mathrm{P}_{l d h L}\right)$ and lacking the signal peptide sequences. Thus, NC8OxdC strain expressing biologically active OxdC at intracellular level and degrading $77 \%$ of oxalate under in vitro condition (Figure 2). Whereas the wild type $L$. plantarum WCFS1 unable to degrade the oxalate as expected.

\section{Oxalate degrading recombinant $L A B$ improved primary health of hyperoxaluric rat}

Control rats (group I), received standard chow, and experimental rats (group II, III, IV and V), which received oxalate mixed food stayed healthy and gained weight. However with time, experimental rats gained significantly lesser weight than control $(P<0.05)$, while rats in

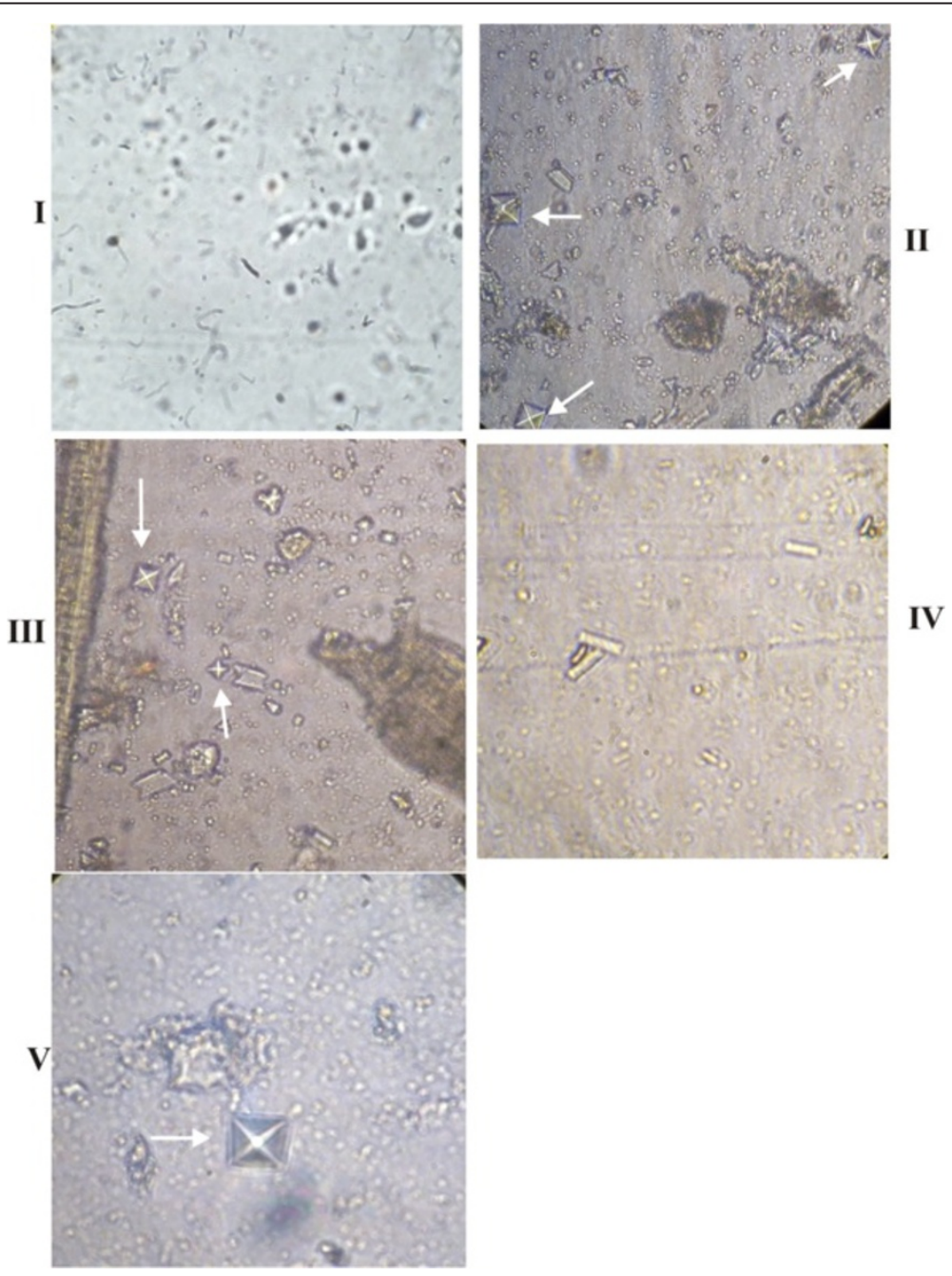

Figure 5 Microscopy examinations of CaOx crystals in experimental rat urine at 20X magnification. I, II, III, IV and V represent the respective group of rat. Arrow indicates the $\mathrm{CaOx}$ crystals urine sample of respective group rats. 
groups IV and V receiving the recombinant L. plantarum WCFS1OxdC and NC8OxdC respectively gained more weight than groups II and III $(P<0.05$, Table 2$)$. Urinary $\mathrm{pH}$ was seen lower in experimental rats than control $(P<0.05$, Table 2$)$ and $\mathrm{pH}$ of group IV and $\mathrm{V}$ showed increased level than group II and III $(P<0.05)$.

Urinary excretion of creatinine increased with time in all animals but it was significantly higher in experimental group than control $(P<0.05)$. However, at the end of experiment (Day 28), mean value of creatinine in groups IV and $\mathrm{V}$ showed significantly lower $(P<0.05)$ against group II and III rats (Table 2). Excretion of uric acid in groups II and III rats showed significant increase $(P<0.05)$ when compared to group I, IV and V (Table 2).

\section{Rats artificially colonized by recombinant $L A B$ reduced urinary oxalate excretion}

Compared to baseline values of urinary oxalate (UOx), the excretion was significantly increased in all groups $(P<0.05)$. By days 7, 14, 21 and 28, excretion of urinary oxalate in groups II, III and V showed significantly increased level than group I $(P<0.05)$. On the other hand, the excretion of oxalate in group IV rats showed significant variations on day 7,14 and 21 when compared to group I $(P<0.05)$, whereas, on $28^{\text {th }}$ day no significant variation was observed (Figure 3A). When the comparisons were made between group II and treated groups (III, IV and V) the UOx excretion on day 21 and 28, groups IV and V rats showed significant reduction than group II $(P<0.05)$. Similarly, when compared to non-recombinant bacterial treated group III, significant decrease of UOx excretion was seen in groups IV and V $(P<0.05)$, at the end of experiment (Figure 3A).

Urinary calcium on baseline does not show any significant change in all groups. Compared to the group I rats calcium level was increased significantly in all groups during the experimental days $(P<0.05)$. While compared to group II and III, the urinary calcium level dropped significantly in group IV on $21^{\text {st }}$ and $28^{\text {th }}$ day $(P<0.05)$, and group $\mathrm{V}$ shows significantly lower level against group II and III rats at $28^{\text {th }}$ day $(P<0.05$, Figure $3 B)$. Urea level of all groups at baseline, $7^{\text {th }}, 14^{\text {th }}$ and $21^{\text {st }}$ day did not show any significant difference against group I, whereas on $28^{\text {th }}$ day the group II and III showed significantly increased level than group I rats $(P<0.05)$. On the other hand, significantly decreased level of urea was observed in groups IV and V against groups II and III $(P<0.05$, Figure $3 C)$.

\section{Recombinant $L$. plantarum survived in rat intestine}

The colony forming units (CFU) method and PCR was used to detect the presence of live recombinant and nonrecombinant $L$. plantarum in the intestine of treated rats. Mean colony forming units (CFU) per gram of feces in group III, IV and V was $6.00 \pm 0.13$ (L. plantarum WCFS1), $6.24 \pm 0.12$ (WCFS1OxdC) and $6.10 \pm 0.10(\mathrm{NC} 8 \mathrm{OxdC})$ respectively (Figure $4 \mathrm{~A})$. Whereas, no strains were detected in the feces of groups I and II. PCR confirmed that the fecal DNA in group IV and V rats alone produces the amplicon corresponding to OxdC gene (1.2 kb) (Figure 4B).

\section{Prevention of crystalluria in recombinant treated rats}

All experimental rats were examined for the presence of $\mathrm{CaOx}$ crystal in urine after the administration of nonrecombinant and recombinant $L$. plantarum. Group I control rats urine was devoid of any $\mathrm{CaOx}$ crystal throughout experimental period. By day 28, rats in groups II and III showed high score $(2+)$ of $\mathrm{CaOx}$ crystal, while group V urine shows low score (1+). The group IV rats did not show any $\mathrm{CaOx}$ crystal (Figure 5).

\section{Recombinant $L$. plantarum maintained normal serum parameters in hyperoxaluric rats}

Blood urea nitrogen and creatinine ratio (BUN/Creatinine) was calculated to predict the renal function. The mean value of BUN/Creatinine ratio in groups II and III rats was $41.04 \pm 1.68$ and $40.04 \pm 0.54$ respectively, against group I $(37.52 \pm 1.30)$. Whereas groups IV and $\mathrm{V}$ showed $34.61 \pm 1.46$ and $36.35 \pm 1.19$, which clearly reveal the significant difference in group II and III $(P<0.05)$ than group I. The uric acid was predicted to be increased in groups II and III against group I $(P<0.05)$. However, no significant difference was observed in groups IV and V against group I (Table 3). In order to predict the inflammation, $\mathrm{C}$-reactive protein (CRP) level was measured in the serum sample of all groups. When compared to control group, significantly

Table 3 Serum profile

\begin{tabular}{llllll}
\hline Parameters & Group I $(\mathbf{n}=\mathbf{6})$ & Group II & Group III & Group IV & Group V \\
\hline Total Protein $(\mathbf{m g} / \mathbf{d l})$ & $7.71 \pm 0.45$ & $6.24 \pm 0.49^{\mathbf{a}^{*}}$ & $6.63 \pm 0.48^{\mathbf{a}^{*}}$ & $6.34 \pm 0.33^{\mathbf{a}^{*}}$ & $6.46 \pm 0.41^{\mathbf{a}^{*}}$ \\
Uric acid $(\mathbf{m g} / \mathbf{d l})$ & $4.52 \pm 0.33$ & $6.61 \pm 0.15^{\mathbf{a}^{*}}$ & $5.91 \pm 0.25^{\mathbf{a}^{*}}$ & $4.35 \pm 0.22^{\mathbf{b}^{*} \mathbf{c}^{*}}$ & $5.06 \pm 0.35^{\mathbf{b}^{*} \mathbf{c}^{*}}$ \\
Calcium (mg/dl) & $12.46 \pm 1.27$ & $11.38 \pm 1.18$ & $10.95 \pm 1.25$ & $10.83 \pm 0.92$ & $10.81 \pm 1.36$ \\
BUN/ Creatinine ratio & $37.52 \pm 1.30$ & $41.04 \pm 1.68^{\mathbf{a}^{*}}$ & $40.04 \pm 0.54^{\mathbf{a}^{*}}$ & $34.61 \pm 1.46^{\mathbf{b}^{*} \mathbf{c}^{*}}$ & $36.35 \pm 1.19^{\mathbf{b}^{*}} \mathbf{c}^{*}$ \\
CRP $(\boldsymbol{\mu g} / \mathbf{m l})$ & $43.35 \pm 2.18$ & $59.72 \pm 2.49^{\mathbf{a}^{*}}$ & $61.92 \pm 2.37^{\mathbf{a}^{*}}$ & $50.75 \pm 2.01^{\mathbf{a}^{*} \mathbf{b}^{*} \mathbf{c}^{*}}$ & $53.73 \pm 2.74^{\mathbf{a}^{*} \mathbf{b}^{*} \mathbf{c}^{*}}$ \\
\hline
\end{tabular}

${ }^{a}$ Data are expressed as mean \pm SD. Comparisons are made against Group I (Control) ${ }^{\text {, }}$, Group II (lithiatic control) ${ }^{b}$ and Group III (Non-recombinant strain) ${ }^{c}$

$a^{*} b^{*}$ and ${ }^{c^{*}}$ indicates the mean value is significant at $p<0.05$ against group I, II and III correspondingly. $n=6$ rats each group. 
increased level of CRP was observed in experimental groups. The serum protein level of experimental groups (II, III, IV and V) showed significant decrease against control $(P<0.05$, Table 3$)$.

\section{Recombinant $L$. plantarum administered rats reduced oxalate level in kidney}

Oxalate concentration in kidney tissue homogenate of groups II, III and V showed significant increase $(P<0.05)$ when compared to groups I and IV rats. However, the recombinant $L$. plantarum administered groups IV and $\mathrm{V}$ showed significantly decreased level of oxalate compared to group II and III $(P<0.05$, Figure $6 \mathrm{~A})$. The concentration of calcium level significantly increased in groups II and III against groups I, IV and V rats $(P<0.05$, Figure 6B).

\section{Gene expression analysis and renal histopathology revealed reversal of kidney stone-induced damage in hyperoxaluric rats}

Renal function was examined by using semi-quantitative PCR for renin, $A C E$ and $O P N$ expression. The upregulation of renin mRNA was observed in groups II and III when compared to group I rats. While the recombinant bacterial treated group IV and V shows significant reduction in mRNA level compared to group II and III. The down regulations of ACE, OPN mRNA were seen in groups II, III, IV and V rats (Figure 7A, B). Histopathological examination of kidney sections of group I rats showed normal histological structures. Group II and III rats showed a reduced number of glomeruli and large areas of red blood cell casts with dialated tubules. Stroma showed hemorrhage and blood vessels were congested and thickened. Sections obtained from rats in the group IV administered with WCFS1OxdC revealed normal glomeruli with no red blood cast, but slight tubular necrosis. Examination of stroma shows areas of hemorrhage. Similarly, group V rats that received NC8OxdC showed normal glomeruli, but high tubular necrosis and congested blood vessels. The $\mathrm{CaOx}$ crystals were examined by pizzolato staining and also by using polarized microscopy. It revealed no incidence of $\mathrm{CaOx}$ crystal deposition in group I whereas as high score $(4+)$ of $\mathrm{CaOx}$ crystals in groups II and III rats. However, group IV showed no identifiable crystal deposits in the kidneys and group $\mathrm{V}$ showed significantly lower score (1+) (Figure 8).

\section{Discussion}

Dietary oxalate is a major contributor to urinary oxalate (UOx) excretion in humans [4]. The identification of intestinal oxalate degrading bacteria provided a new direction for the reduction of UOx [24]. The present study is to examine the efficacy of heterologous OxdC expressing
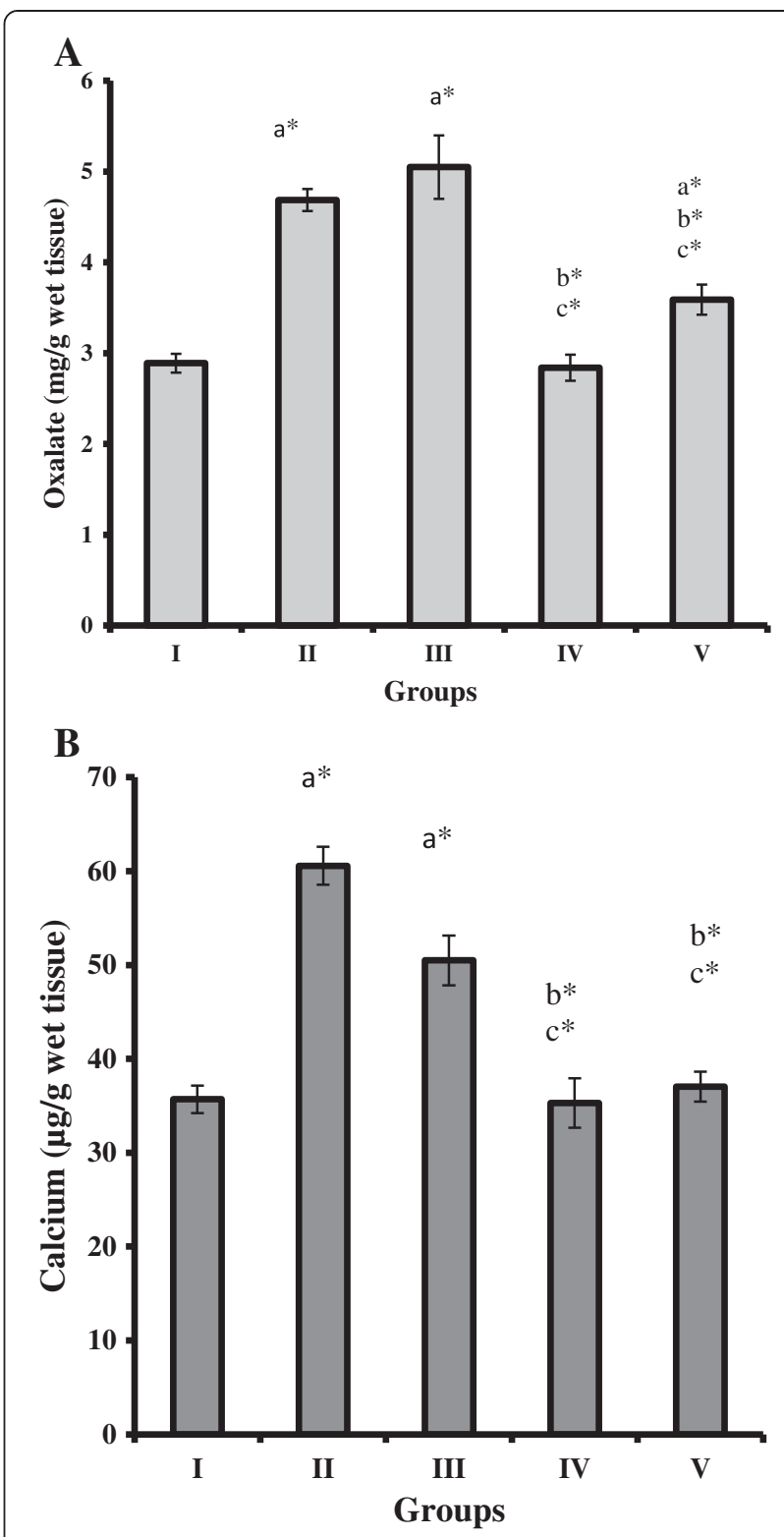

Figure 6 Oxalate and calcium concentrations in kidney of control and experimental rats. (A) Oxalate concentrations in the kidney of control and experimental rats ( $n=6$ rats per group). (B) Calcium concentrations in the kidney of control and experimental rats $(n=6$ rats per group). Comparisons are made against Group I (Control), Group II (lithiatic control) $)^{b}$ and Group III (Non-recombinant strain) ${ }^{c}$. The mean value is significant at $p<0.05$.

and secreting recombinant L. plantarum to degrade the intestinal oxalate thereby preventing hyperoxaluria and $\mathrm{CaOx}$ urolithiasis in rats.

Previously, we reported in vitro degradation of oxalate by recombinant $L$. plantarum expressing heterologous OxdC at intracellular level [17]. Since the expression was intracellular, we made an attempt to express OxdC extracellularly to increase the oxalate degradation 


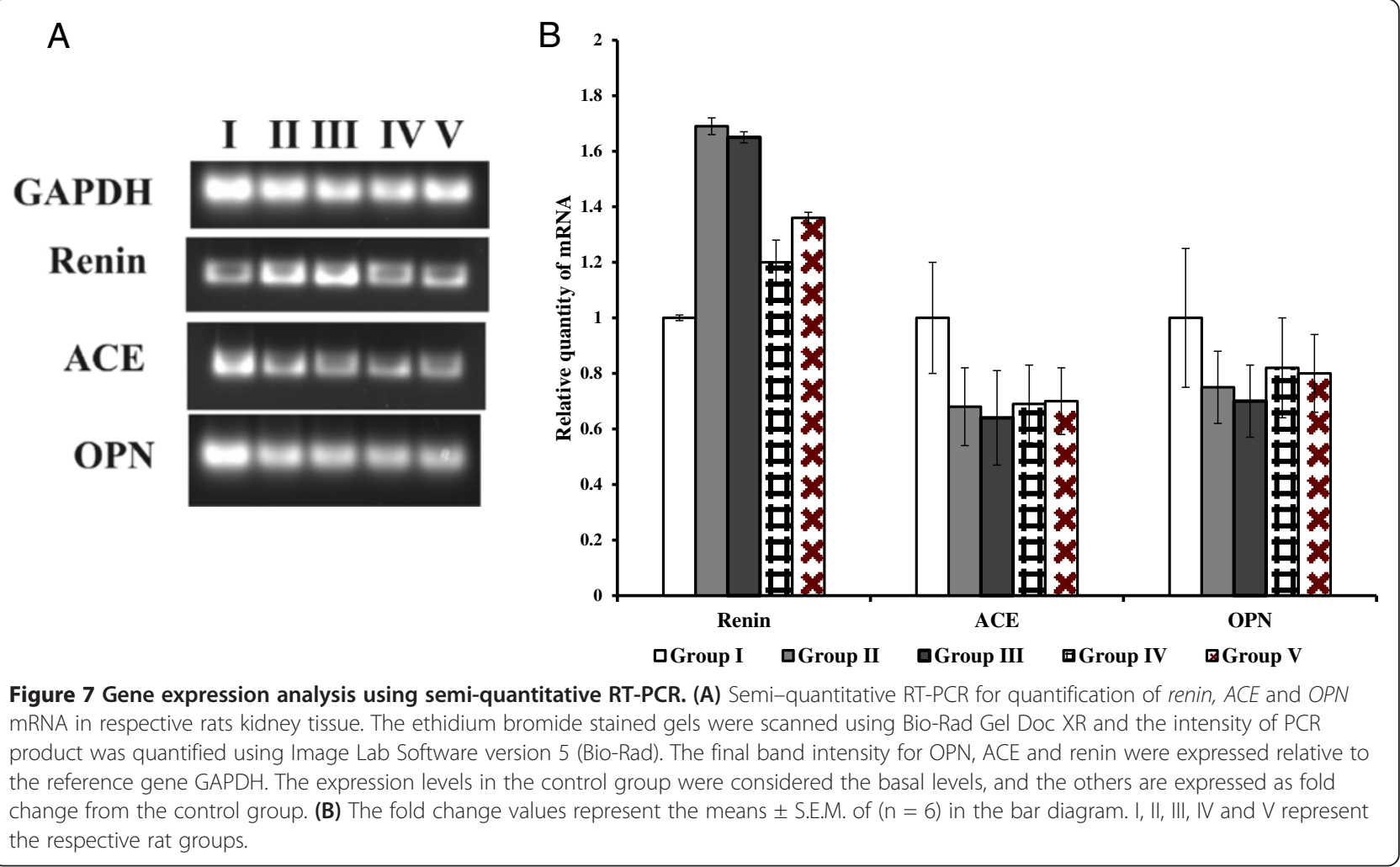

efficiency. Sasikumar et al. [25] analyzed the two homologous signal peptide (SP) such as Lp_0373 and Lp_3050 of L. plantarum for the extracellular expression OxdC under inducible condition and results shown that the SP (Lp_0373) efficiently secrete the OxdC than the SP (Lp_3050). Later on, by using previously characterized homologous promoter $\left(\mathrm{P}_{\text {ldhL }}\right)$ and signal peptide (Lp_0373) sequences, the genetically modified constitutively OxdC-secretory WCFS1OxdC strain was developed [16]. The resulting L. plantarum strain found to be very efficient for secretion of $\mathrm{OxdC}$ and degradation of extracellular oxalate. Here, the intragastric oxalate degrading efficiency of intracellular and extracellular OxdC expressing recombinant $L$. plantarum was evaluated in rats. Results of plasmid segregation analysis reveal daily administration of recombinant $L$. plantarum is vital since the L. plantarum lost almost $70-90 \%$ of erythromycin-based plasmid [16]. Hence, artificial intestinal colonization and oxalate degradation in rat was established via the daily load, as a result the expression of OxdC was retained. In future, the plasmid can be stabilized by constructing mutants lacking essential genes like alr (alanine racemase), which can be complimented by adding back via the plasmid [26].

$O$. formigenes is efficient in oxalate degradation and had been proposed for its application for degrading intestinal oxalate $[10,27,28]$. Numerous studies have linked the absence of $O$. formigenes to higher UOx excretion $[29,30]$. Reports revealed no significant difference in UOx excretion between patients who tested positive or negative for $O$. formigenes [31]. In addition, colonization of $O$. formigenes in the gut require oral oxalate supplements [9]. Sidhu et al. [27] demonstrated that when oxalate is removed from the diet, artificially colonized rats lose colonization within 5 days. Since the uses of O. formigenes in mitigation of intestinal oxalate have difficulty, here we tried alternatively by using recombinant L. plantarum secreting OxdC protein extracellular level for degradation of intestinal oxalate.

The significant reduction of urinary oxalate excretion in group IV and V rats clearly illustrates the degradation of dietary oxalate by the presence of recombinant L. plantarum WCFS1OxdC and NC8OxdC. Hyperoxaluric conditions were observed in the absence of recombinant strain in group II and III rats. Even though, groups IV and $\mathrm{V}$ rats showed significant reduction in UOx excretion, the higher reduction was seen in group IV (43\%) than in group V (30\%) which suggested that intestinal oxalate in group IV is better degraded than in group $\mathrm{V}$ rats.

When compared to group II, $40 \%$ and $25 \%$ of total oxalate concentration was reduced in the kidney tissue of group IV and V rats and $45 \%$ and $30 \%$ of oxalate reduction when compared to wild type L. plantarum treated group III rats respectively. The higher reduction of 


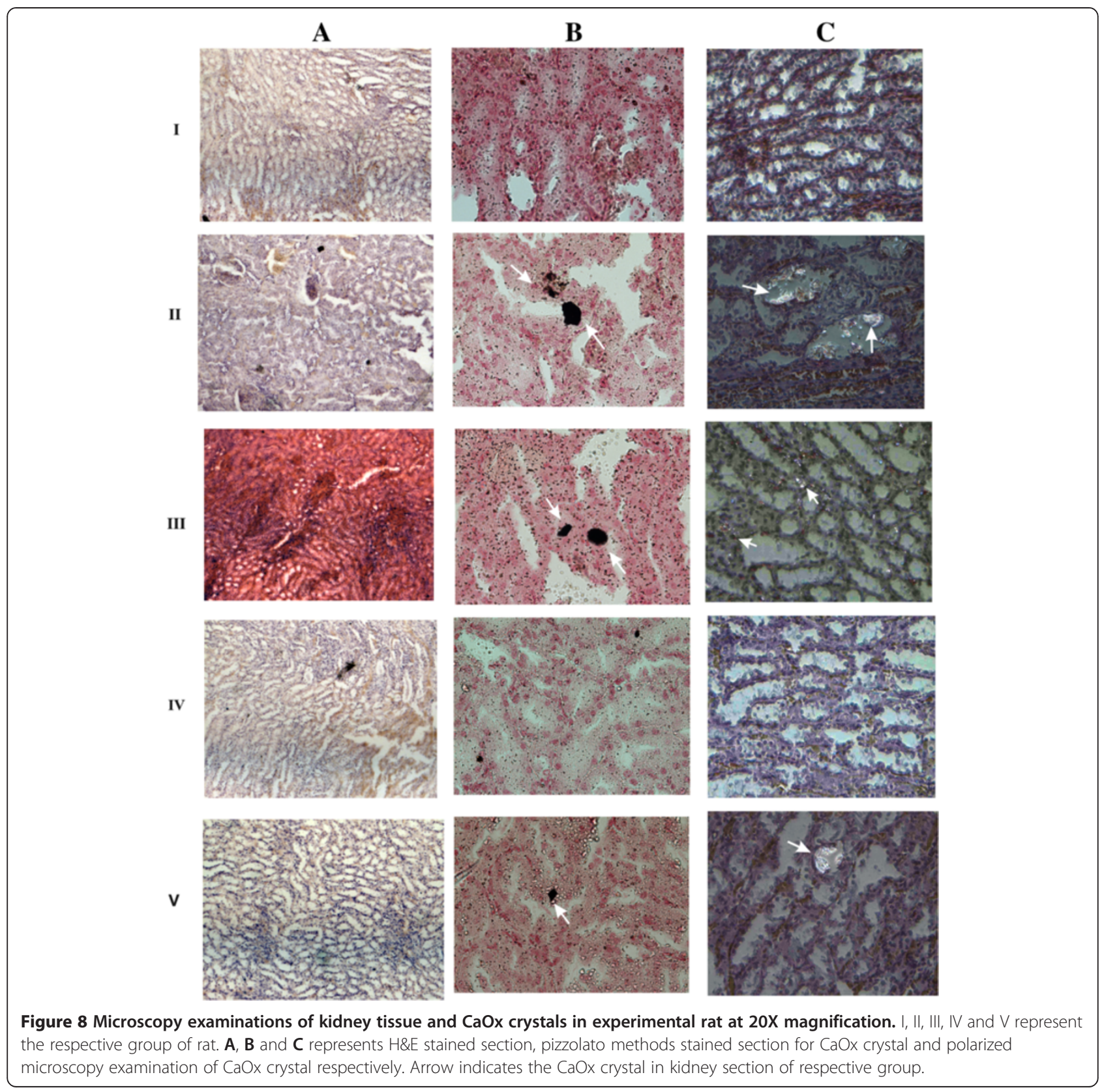

oxalate in kidney tissue of group IV rats administrated with recombinant WCFS1OxdC strain was associated with the secretion of $\mathrm{OxdC}$, which prevented hyperoxaluria effectively compared to non-secretory NC8OxdC strain treated rats (group V) by promoting higher degradation of intestinal oxalate. Increase in calcium and oxalate content in the renal tissue of group II and III were associated with oxalate supplemented diet. Orally administered Escherichia coli (E. coli) expressed recombinant B. subtilis OxdC has substantially declined the UOx level in experimental rat [13]. Oral therapy with crystalline, cross-linked formulation of the OxdC in mice diminishes symptoms of hyperoxaluria and urolithiasis [14]. Furthermore, orally given formulation of B. subtilis $\mathrm{OxdC}$, was shown to be safe in rats and dogs during short-term toxicity tests [15]. Although, the use of OxdC enzyme to decompose intestinal oxalate was broadly demonstrated, this approach to treat hyperoxaluria can be very expensive and daily load of OxdC was also required. The recombinant $L$. plantarum developed in this study was degrading intestinal oxalate by simply colonizing bacterium in the gut. However, improvement in strategy of artificial colonization of the strain for its use as probiotics is majorly required. 
The significantly lower excretion of urinary urea, uric acid, creatinine and serum BUN/Creatinine ratio, uric acid in recombinant strain administered rats in group IV and $\mathrm{V}$ reveals the oxalate mediated renal damage was protected in rats group by degrading intestinal oxalate and thereby preventing oxalate toxicity. Increased level of urinary creatinine and serum BUN/Creatinine ratio in group II and III rats associated with renal tissue damage and functional abnormalities by the oxalate induced toxicity. The changes in the urinary $\mathrm{pH}$ of rats in group II and III might be associated with the distal tubular dysfunction.

A significant increase in the expression of renin mRNA in kidneys of groups II and III rats suggesting higher oxalate stress in kidney due to the oxalate diet. While, reversed expression of renin mRNA in group IV and $\mathrm{V}$ indicating that oxalate stress in the kidney was reduced due to the degradation of oxalate in intestine by the administered recombinant L. plantarum. Similarly, the increase in renin mRNA expression is associated with hyperoxaluria and $\mathrm{CaOx}$ crystal deposition [32].

Microscopic examination of urinary sediments of oxalate-diet fed rats in groups II and III showed a high score of $\mathrm{CaOx}$ crystal than rats in groups IV and $\mathrm{V}$ at the end of experimental period. Earlier reports also suggested that administration of oxalate supplemented diet induced $\mathrm{CaOx}$ crystal in urine [33]. Polarized microscopic examination of paraffin kidney sections revealed no significant $\mathrm{CaOx}$ crystal in group IV rats that received OxdC-secreting strain (WCFS1OxdC), whereas, group $\mathrm{V}$ rats administered with non-secretory strain (NC8OxdC) showed lower CaOx crystal deposition. This observation reveal that kidney of group IV rats was better protected from oxalate toxicity compared to group V. But, group III rats receiving wild type $L$. plantarum showed higher crystal score, suggesting that the wild type strain does not degrade the intestinal oxalate that lead to higher crystal aggregation. Similar results were also observed in pizzolato stained kidney sections of experimental rat groups (I, II, III, IV and V). Histopathology observation of kidney tissue of groups II and III rats showed kidney damage, while the group IV and V rats kidney showed normal glomeruli with moderate and high necrosis respectively. The increased level of CRP in the serum of group II and III rats was associated with the renal inflammation and renal function abnormalities, which was also clearly observed in histological studies. However, the significantly decreased CRP levels were observed in groups IV and V compared to groups II and III rats, that indicates renal damage was protected due to the reduction of oxalate toxicity by the recombinant L. plantarum.

The present study showed the artificial colonization of L. plantarum harboring the plasmid pLdhl0373OxdC and pLdhlOxdC containing oxalate degrading gene $(\operatorname{oxd} C)$ decrease urinary oxalate excretion and $\mathrm{CaOx}$ crystal deposition in rats due to the degradation of dietary oxalate in intestine by $\mathrm{OxdC}$ expressing and secreting recombinant $L$. plantarum. However, using them as a probiotic require improvement by stabilizing the plasmid by constructing mutant strain lacking essential genes (eg., thyA or alr).

\section{Conclusion}

In conclusion, the current study indicate that daily oral administration of OxdC secretory L. plantarum WCFS1OxdC in rats associated with decreased excretion of urinary oxalate and reduced risk of calcium oxalate crystal formation. The results provide an evidence of colonization with recombinant $L$. plantarum capable of reducing urinary oxalate excretion which reflects increased intestinal oxalate degradation, leaving less oxalate available for absorption. Further, the findings of the above study help to develop a biologically contained recombinant bacterium with foodgrade selection marker, used as a probiotic for the treatment of hyperoxaluria and calcium oxalate stone disease.

\section{Additional files}

Additional file 1: Table S1. Primers used in this work.

Additional file 2: Table S2. Kits used for biochemical parameters analysis.

Additional file 3: RNA isolation and Semi - Quantitative RT-PCR.

\section{Abbreviations}

CaOx: Calcium Oxalate; UOx: Urinary Oxalate; L. plantarum: Lactobacillus plantarum; O. formigenes: Oxalobacter formigenes; LAB: Lactic acid bacteria; OxdC: Oxalate decarboxylase; SP: Signal Peptide.

Competing interests

The author(s) declare that they have no competing interests.

\section{Authors' contributions}

PS, SG, KA and GSS: Study concept and design of the work. PS, SG, AA and EP: Acquisition of data. PS, KA and AA: Analysis and interpretation of data. PS, SG, KA, W, SS and GSS: Drafting of the manuscript. GSS: Critical revision of the manuscript for important intellectual content. PS and AA: Statistical analysis. All authors read and approved the final version of the manuscript.

\section{Acknowledgments}

The authors express their gratitude to Professor Michiel Kleerebezem, Wageningen, Centre for Food Sciences, The Netherlands, for providing the strain Lactobacillus plantarumWCFS1. The authors also wish to thank Dr. Stephen Bornemann for providing the plasmid pLB36 consisting oxdC gene. We also express thanks to Dr. K. Usha Rani MD, Pathologist, Department of Histopathology, Apollo Hospital, and Dr S.P. Arivarasan, Pathologist, Bose Clinical Laboratory, Madurai, India for the kidney histopathology studies and also we extend our thanks to Dr Sukesh Chandran Nair, Department of transfusion medicine and Immunohematology, Christian Medical College, Vellore, India for helping in polarized microscopy for examining $\mathrm{CaOx}$ crystal. This work was supported by University Grants Commission (UGC), and Department of Biotechnology (DBT), New Delhi, India through IPLS program. The authors also thank UGC and DST for the central instrumentation facility at SBS, MKU through CEGS, CAS, NRCBS, DST-FIST, and DST-PURSE program. 


\section{Author details}

${ }^{1}$ Department of Biochemistry, Centre for Advanced Studies in Organismal and Functional Genomics, School of Biological Sciences, Madurai Kamaraj University, Madurai 625 021, India. ${ }^{2}$ INSERM-U844, Insitut des Neuroscience de Montpellier Building, Hopital St. Eloi, 34091 Montpellier, France.

Received: 18 March 2014 Accepted: 19 August 2014

Published: 30 August 2014

\section{References}

1. Stamatelou KK, Francis ME, Jones CA, Nyberg LM, Curhan GC: Time trends in reported prevalence of kidney stones in the United States: 1976-1994. Kidney Int 2003, 63:1817-1823.

2. Hesse A, Siener R: Current aspects of epidemiology and nutrition in urinary stone disease. World J Urol 1997, 15:165-171.

3. Curhan GC, Willett WC, Speizer FE, Stampfer MJ: Twenty-four-hour urine chemistries and the risk of kidney stones among women and men. Kidney Int 2001, 59:2290-2298.

4. Holmes RP, Goodman HO, Assimos DG: Contribution of dietary oxalate to urinary oxalate excretion. Kidney Int 2001, 59:270-276.

5. Siener R, Hönow R, Voss $S$, Seidler A, Hesse A: Oxalate content of cereals and cereal products. J Agric Food Chem 2006, 54:3008-3011.

6. Voss S, Hesse A, Zimmermann DJ, Sauerbruch T, von Unruh GE: Intestinal oxalate absorption is higher in idiopathic calcium oxalate stone formers than in healthy controls: measurements with the [(13)C2]oxalate absorption test. J Urol 2006, 175:1711-1715.

7. Parivar F, Low RK, Stoller ML: The influence of diet on urinary stone disease. J Urol 1996, 155:432-440.

8. Allison MJ, Dawson KA, Mayberry WR, Foss JG: Oxalobacter formigenes gen. nov., sp. nov.: oxalate-degrading anaerobes that inhabit the gastrointestinal tract. Arch Microbio/ 1985, 141:1-7.

9. Siener R, Bangen U, Sidhu H, Hönow R, von Unruh G, Hesse A: The role of Oxalobacter formigenes colonization in calcium oxalate stone disease. Kidney Int 2013, 83:1144-1149.

10. Hatch M, Cornelius J, Allison M, Sidhu H, Peck A, Freel RW: Oxalobacter sp. reduces urinary oxalate excretion by promoting enteric oxalate secretion. Kidney Int 2006, 69:691-698

11. Lieske JC, Tremaine WJ, De Simone C, O'Connor HM, Li X, Bergstralh EJ, Goldfarb DS: Diet, but not oral probiotics, effectively reduces urinary oxalate excretion and calcium oxalate super saturation. Kidney Int 2010, 78:1178-1185.

12. Tanner A, Bornemann S: Bacillus subtilis YvrK is an acid-induced oxalate decarboxylase. J Bacteriol 2000, 182:5271-5273.

13. Jeong BC, Han DH, Seo SI, Jeon SS, Lee HM, Choi HY, Park YH, Kim: YvrK gene recombinant $E$. coli reduce the concentration of urine oxalate in transient hyperoxaluria rat model. Korean J Urol 2009, 50:1022-1026.

14. Grujic D, Salido EC, Shenoy BC, Langman CB, McGrath ME, Patel RJ, Rashid A, Mandapati S, Jung CW, Margolin AL: Hyperoxaluria is reduced and nephrocalcinosis prevented with an oxalate-degrading enzyme in mice with hyperoxaluria. Am J Nephrol 2009, 29:86-93.

15. Cowley AB, Poage DW, Dean RR, Meschter CL, Ghoddusi M, Li QS, Sidhu H: 14-day repeat-dose oral toxicity evaluation of oxazyme in rats and dogs. Int J Toxicol 2010, 29:20-31.

16. Sasikumar P, Gomathi S, Anbazhagan K, Ebinezer Baby A, Sangeetha J, Selvam GS: Genetically engineered Lactobacillus plantarum WCFS1 constitutively secreting heterologous oxalate decarboxylase and degrading oxalate under in vitro. Curr Microbio/ 2014, doi:10.1007/s00284-014-0644-2.

17. Anbazhagan K, Sasikumar P, Gomathi S, Priya HP, Selvam GS: In vitro degradation of oxalate by recombinant Lactobacillus plantarum expressing heterologous oxalate decarboxylase. J Appl Microbio/ 2013 115:880-887.

18. Wiessner JH, Garrett MR, Hung LY, Wille DF, Mandel NS: Improved methodology to induce hyperoxaluria without treatment using hydroxyproline. Urol Res 2011, 39:373-377.

19. Kleerebezem M, Boekhorststraat J, van Kranenburg R, Molenaar D, Kuipers OP, Leer R, Tarchini R, Peters SA, Sandbrink HM, Fiers MW, Stiekema W, Lankhorst RM, Bron PA, Hoffer SM, Groot MN, Kerkhoven R, de Vries M, Ursing B, de Vos WM, Siezen RJ: Complete genome sequence of Lactobacillus plantarum WCFS1. Proc Natl Acad Sci USA 2003, 100:1990-1995.
20. Khan SR, Glenton PA, Byer KJ: Modeling of hyperoxaluric calcium oxalate nephrolithiasis: experimental induction of hyperoxaluria by hydroxy-L-proline. Kidney Int 2006, 70:914-923.

21. Hodgkinson A, Williams A: An improved colorimetric procedure for urine oxalate. Clin Chim Acta 1972, 36:127-132.

22. Vanachayangkul $P$, Chow N, Khan SR, Butterweck V: Prevention of renal crystal deposition by an extract of Ammi visnaga $L$. and its constituents khellin and visnagin in hyperoxaluric rats. Urol Res 2011, 39:189-195.

23. Pizzolato P: Histochemical Recognition of Calcium Oxalate. J Histochem Cytochem 1964, 12:333-336.

24. Campieri C, Campieri M, Bertuzzi V, Swennen E, Matteuzzi D, Stefoni S, Pirovano F, Centi C, Ulisse S, Famularo G, De Simone C: Reduction of oxaluria after an oral course of lactic acid bacteria at high concentration. Kidney Int 2001, 60:1097-1105.

25. Sasikumar P, Gomathi S, Anbazhagan K, Selvam GS: Secretion of Biologically Active Heterologous Oxalate Decarboxylase (OxdC) in Lactobacillus plantarum WCFS1 Using Homologous Signal Peptides. Biomed Res Int 2013, 2013:280432

26. Nguyen TT, Mathiesen G, Fredriksen L, Kittl R, Nguyen TH, Eijsink VGH, Haltrich D, Peterbauer CK: A food-grade system for inducible gene expression in Lactobacillus plantarum using an alanine racemaseencoding selection marker. J Agric Food Chem 2011, 59:5617-5624.

27. Sidhu H, Allison MJ, Chow JM, Clark A, Peck AB: Rapid reversal of hyperoxaluria in a rat model after probiotic administration of Oxalobacter formigenes. J Urol 2001, 166:1487-1491.

28. Hoppe B, Beck B, Gatter N, von Unruh G, Tischer A, Hesse A, Laube N, Kaul $P$, Sidhu H: Oxalobacter formigenes: a potential tool for the treatment of primary hyperoxaluria type 1. Kidney Int 2006, 70:1305-1311.

29. Sidhu H, Hoppe B, Hesse A, Tenbrock K, Brömme S, Rietschel E, Peck AB: Absence of Oxalobacter formigenes in cystic fibrosis patients: a risk factor for hyperoxaluria. Lancet 1998, 352:1026-1029.

30. Kwak C, Kim HK, Kim EC, Choi MS, Kim HH: Urinary oxalate levels and the enteric bacterium Oxalobacter formigenes in patients with calcium oxalate urolithiasis. Eur Urol 2003, 44:475-481.

31. Mikami K, Akakura K, Takei K, Ueda T, Mizoguchi K, Noda M, Miyake M, Ito H: Association of absence of intestinal oxalate degrading bacteria with urinary calcium oxalate stone formation. Int J Urol 2003, 10:293-296.

32. Umekawa T, Hatanaka Y, Kurita T, Khan SR: Effect of angiotensin II receptor blockage on osteopontin expression and calcium oxalate crystal deposition in rat kidneys. J Am Soc Nephrol 2004, 15:635-644.

33. Khan SR, Glenton PA, Byer KJ: Dietary oxalate and calcium oxalate nephrolithiasis. J Urol 2007, 178:2191-2196.

doi:10.1186/s12929-014-0086-y

Cite this article as: Sasikumar et al:: Recombinant Lactobacillus plantarum expressing and secreting heterologous oxalate decarboxylase prevents renal calcium oxalate stone deposition in experimental rats. Journal of Biomedical Science 2014 21:86.

\section{Submit your next manuscript to BioMed Central and take full advantage of:}

- Convenient online submission

- Thorough peer review

- No space constraints or color figure charges

- Immediate publication on acceptance

- Inclusion in PubMed, CAS, Scopus and Google Scholar

- Research which is freely available for redistribution 